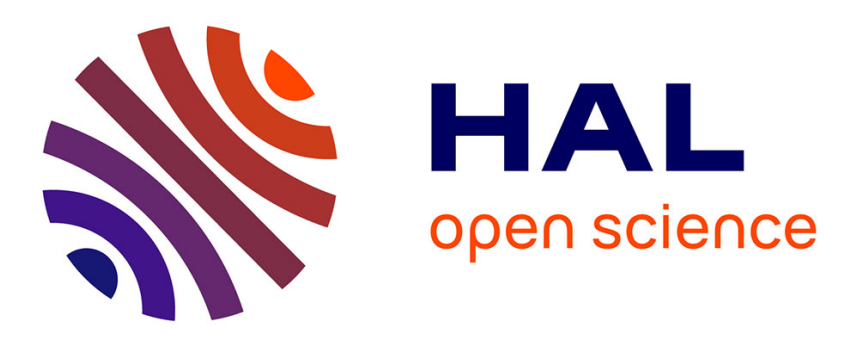

\title{
The 2000 Tottori earthquake: a shallow aerthquake with no surface rupture and slip properties controlled by depth.
}

\author{
F. Semmane, Fabrice Cotton, Michel Campillo
}

\section{- To cite this version:}

F. Semmane, Fabrice Cotton, Michel Campillo. The 2000 Tottori earthquake: a shallow aerthquake with no surface rupture and slip properties controlled by depth.. Journal of Geophysical Research: Solid Earth, 2005, 110 (B3), pp.B03306. 10.1029/2004JB003194 . hal-00109287

\section{HAL Id: hal-00109287 \\ https://hal.science/hal-00109287}

Submitted on 19 Feb 2021

HAL is a multi-disciplinary open access archive for the deposit and dissemination of scientific research documents, whether they are published or not. The documents may come from teaching and research institutions in France or abroad, or from public or private research centers.
L'archive ouverte pluridisciplinaire HAL, est destinée au dépôt et à la diffusion de documents scientifiques de niveau recherche, publiés ou non, émanant des établissements d'enseignement et de recherche français ou étrangers, des laboratoires publics ou privés. 


\title{
The 2000 Tottori earthquake: A shallow earthquake with no surface rupture and slip properties controlled by depth
}

\author{
Fethi Semmane, Fabrice Cotton, and Michel Campillo \\ Laboratoire de Géophysique Interne et Tectonophysique, Université Joseph Fourier, Grenoble, France \\ Received 27 May 2004; revised 16 December 2004; accepted 3 January 2005; published 26 March 2005.
}

[1] The $M_{w} 6.8$ Tottori earthquake, Japan, does not exhibit any surface trace but was particularly well instrumented. Strong motion displacement records and GPS coseismic data are used to constrain the evolution of the slip on the fault plane in time and space. We adopt in this study a two-plane fault geometry based on aftershock distributions and analysis of close station records. In a first step, our inversion allowed surface slip. The model obtained has a significant surface slip, which contradicts the absence of clear surface slip reported by geologists. In a second step, models with no slip at the surface (buried faults), compatible with geological observations, have been tested. The tests with different fault depths show that when slip is allowed to occur close to the surface, the fit to seismological and geodetic data is increased. These tests confirm that slip actually occurred at shallow depth. Despite the nonuniqueness of the solution, all the inverted source models show (1) a large slip amplitude patch at a depth of about 4-5 km and (2) relatively small slip in the hypocentral area. The rupture velocity is about $2750 \mathrm{~m} / \mathrm{s}$ in the asperity region. The total rupture duration is about $8 \mathrm{~s}$. The slip distribution seems to be controlled by the variation of fault properties with depth. Another feature that could control the rupture of this earthquake is a fault plane almost perpendicular to the main fault NW of the epicenter, which apparently inhibits further rupture propagation.

Citation: Semmane, F., F. Cotton, and M. Campillo (2005), The 2000 Tottori earthquake: A shallow earthquake with no surface rupture and slip properties controlled by depth, J. Geophys. Res., 110, B03306, doi:10.1029/2004JB003194.

\section{Introduction}

[2] The Tottori, Japan, earthquake $\left(M_{w}=6.6 \sim 6.8\right)$ occurred on 6 October 2000 at 0430:18.07 UT. The epicenter is located at $35.269^{\circ} \mathrm{N}$ and $133.357^{\circ} \mathrm{E}$ [Iwata and Sekiguchi, 2002]. The 2000 Tottori earthquake was the first important earthquake recorded by the KIK-net network (National Research Institute for Earth Science and Disaster Prevention) and thus provides a unique set of near field data (http://www.kik.bosai.go.jp/kik). This accelerometer network, installed after the 1995 Kobe earthquake, consists of sensors located both at the surface and at depth $(100 \mathrm{~m}$ and greater). These data provide the opportunity to compare inversions performed with ground motions recorded at the surface and at depth. The borehole records allow the evaluation of possible site effects that can contaminate surface records and introduce a bias in the source inversion process. In this study, we evaluate the site-effect bias by comparing the kinematic models of the 2000 Tottori earthquake derived from borehole records and from surface records, respectively.

[3] The 2000 Tottori earthquake is an almost pure leftlateral strike-slip event for which different focal depths have been proposed. The different published centroid moment tensor (CMT) solutions also give significantly

Copyright 2005 by the American Geophysical Union. 0148-0227/05/2004JB003194\$09.00 different moments and origin times (Table 1). Furthermore, since there is no clear surface expression of this earthquake, it is almost impossible to derive fault geometry from geological observations. The first goal of this paper is to better constrain the fault geometry and origin time of this earthquake using data from close strong motion stations.

[4] So far, few studies of the rupture of the 2000 Tottori earthquake have been carried out [e.g., Iwata and Sekiguchi, 2002; Peyrat and Olsen, 2004]. The second goal of this paper is to retrieve the source kinematics using a frequency domain inversion procedure [Cotton and Campillo, 1995; Hernandez et al., 1999]. We use both geodetic and strong motion data to better constrain the source properties.

[5] Many moderate earthquakes $\left(M_{w}=6-7\right)$ have produced little or no surface trace such as the 1984 Morgan Hill [Hartzell and Heaton, 1986], the 1989 Loma Prieta [Uhrhammer and Bolt, 1991], the 1992 Joshua Tree, and the northern part of the 1995 Kobe earthquakes [Sekiguchi et al., 2000]. However, even if several recent earthquakes show that large shallow rupture can take place not only on faults that cut the Earth's surface but also on hidden faults, there is a lack of information on how shallow the large slip asperities are. In the present study, we will discuss the minimum depth of the Tottori earthquake's slip area, searching for a rupture model that satisfies near field records and complies with the absence of clear surface slip observations. 
Table 1. CMT Solutions and Inversions ${ }^{\mathrm{a}}$

\begin{tabular}{|c|c|c|c|c|c|}
\hline CMT Inversion & Moment, $\times 10^{18} \mathrm{~N} \mathrm{~m}$ & Magnitude $M_{w}$ & Origin Time, UT & $\begin{array}{c}\text { Hypocentral } \\
\text { Depth, km }\end{array}$ & $\begin{array}{c}\text { Data } \\
\text { Type Used }\end{array}$ \\
\hline ERI & 2.93 & 6.2 & 0430 & 31.3 & Ts \\
\hline USGS & 7.4 & 6.5 & $0430: 23.37$ & 12 & Ts \\
\hline Harvard & 11 & 6.66 & $0430: 25.8$ & 19.9 & Ts \\
\hline $\begin{array}{l}\text { Y. Yagi and M. Kikuchi } \\
\text { (unpublished } \\
\text { manuscript, 2000) }\end{array}$ & 11 & 6.6 & $?$ & 11 & $\mathrm{Ts}+\mathrm{SM}$ \\
\hline Iwata and Sekiguchi [2002] & 19 & 6.8 & 0430:18.07 & 7.8 & SM \\
\hline This study & 14.7 & 6.74 & 0430:18.07 & 14.5 & SM \\
\hline
\end{tabular}

${ }^{a}$ CMT, centroid moment tensor; ERI, Earthquake Research Institute; USGS, U.S. Geological Survey; Ts, teleseismic; SM, strong motions.

[6] The 2000 Tottori earthquake caused relatively moderate damage: 182 people were injured and about 400 buildings destroyed. This low impact is largely due to the fact that the epicenter was located in a mountainous area. Nevertheless earthquakes of this magnitude can be very destructive, like the Kobe earthquake. According to Kagawa et al. [2004], ground motions generated by buried fault are larger than ground motions generated by earthquakes that rupture the surface. It is therefore essential to better constrain the source properties (rupture velocity, subevent size), as knowledge of them is required for strong ground motion simulations for earthquakes scenarios. For this reason, our results will be compared and discussed with the predictions of recent empirical relations between moment magnitude and source properties [Somerville et al., 1999].

\section{Data}

[7] Both seismic waveforms and GPS data are used to constrain the fault model. Strong motion waveforms are inverted alone at first and, in a second step, with the a priori slip distribution deduced from GPS data inversion, as proposed by Hernandez et al. [1999].

\subsection{Strong Motion Data}

\subsubsection{Data Selection and Site Effect Analysis}

[8] To study the general characteristics of the slip history of the 2000 Tottori earthquake, strong motion data from 10 KIK-net stations and 13 K-net stations (http://www.kik. bosai.go.jp) are considered. The station locations are plotted in Figure 1 and are listed in Table 2. A particularity of the KIK-net data is that they provide the opportunity to compare, in the frequency range of kinematics inversions $[0.1-1.0] \mathrm{Hz}$, seismograms recorded at depth $(100-400 \mathrm{~m})$ and at the surface. This comparison shows that surface motions are in general very similar to motions recorded at depth in this frequency range (Figure 2). However, some stations show great discrepancies on one, two or three components. We have observed the following:

[9] 1. The two stations located in the north of the seismogenic area, SMNH11 and SMNH10, have late arrivals that could be explained by surface waves generated in the sediments close to the sea shore. These two stations are not included in the inversion.

[10] 2. The two horizontal surface records from station TTRH02 show evidence of a site effect in the frequency range considered. This site effect has been confirmed by other studies and involves nonlinear soil response [e.g., Bonilla et al., 2003]. The same effect (nonlinear site effect) is observed at station OKYH007 on the two horizontal components and on the E-W component of station SMNH02.

[11] Therefore two data sets were chosen containing recordings showing no obvious complex propagation or site effect contamination. One data set of surface recordings (Table 2) consists of records collected on $11 \mathrm{~K}$-net and 7 surface KIK-net stations, and the "borehole" records data set (Table 2) consists of records collected on 8 borehole KIK-net stations.

\subsubsection{Data Processing and Weighting}

[12] Original acceleration waveforms are band-pass filtered in the frequency range of $0.1-1.0 \mathrm{~Hz}$ using a two-pole Butterworth filter applied forward and backward, resampled to a sampling interval of $0.47 \mathrm{~s}$ and then doubly integrated to obtain the particle displacement. Following the first inversion runs some vertical components were given less weight compared to the horizontal ones, because the vertical component of $\mathrm{S}$ waves is very sensitive to the angle of incidence for small angles. They are not well modeled by our simple one-dimensional (1-D) average velocity structure.

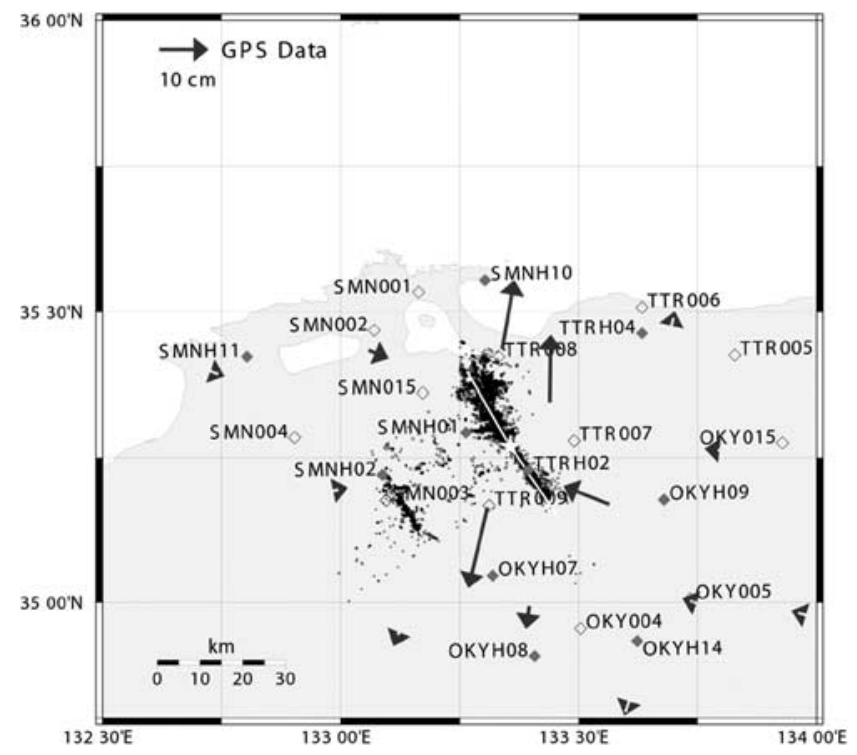

Figure 1. GPS station locations and estimated horizontal vector displacement (arrows), location of the 2000 Tottori earthquake (star), and near-field accelerometric station locations (KIK-net (solid diamonds) and K-net (open diamonds)). Solid line shows the fault trace of the plane adopted in this study. Aftershock locations are from Fukuyama et al. [2003]. 
Table 2. Stations and Records Used in This Study ${ }^{\mathrm{a}}$

\begin{tabular}{|c|c|c|c|c|c|c|c|}
\hline \multirow[b]{2}{*}{ Station } & \multirow{2}{*}{$\begin{array}{l}\text { Distance From } \\
\text { Epicenter, km }\end{array}$} & \multicolumn{3}{|c|}{ Components } & \multirow[b]{2}{*}{ Affiliation } & \multirow{2}{*}{$\begin{array}{c}\text { Surface } \\
\text { Record Set } \\
\end{array}$} & \multirow{2}{*}{$\begin{array}{l}\text { Downhole } \\
\text { Record Set } \\
\end{array}$} \\
\hline & & $\mathrm{N}-\mathrm{S}$ & E-W & U-D & & & \\
\hline SMNH01 & 8 & + & + & + & KIK-net & + & + \\
\hline SMNH02 & 24 & + & + & + & KIK-net & + & + \\
\hline SMNH10 & 31 & - & - & - & KIK-net & - & - \\
\hline SMNH11 & 52 & - & - & - & KIK-net & - & - \\
\hline TTRH02 & 7 & + & + & - & KIK-net & - & + \\
\hline TTRH04 & 33 & + & + & - & KIK-net & + & + \\
\hline OKYH07 & 26 & + & + & + & KIK-net & + & + \\
\hline OKYH08 & 41 & + & + & + & KIK-net & + & + \\
\hline OKYH09 & 32 & + & + & + & KIK-net & + & + \\
\hline OKYH14 & 45 & + & + & - & KIK-net & + & + \\
\hline SMN001 & 33 & - & - & - & K-net & - & \\
\hline SMN002 & 33 & - & - & - & K-net & - & \\
\hline SMN003 & 25 & + & + & - & K-net & + & \\
\hline SMN004 & 40 & + & + & - & K-net & + & \\
\hline SMN015 & 19 & + & + & + & K-net & + & \\
\hline TTR005 & 47 & + & + & - & K-net & + & \\
\hline TTR006 & 37 & + & + & - & K-net & + & \\
\hline TTR007 & 13 & + & + & + & K-net & + & \\
\hline TTR008 & 16 & + & + & + & K-net & + & \\
\hline TTR009 & 13 & + & + & + & K-net & + & \\
\hline OKY004 & 38 & + & + & + & K-net & + & \\
\hline OKY005 & 46 & + & + & + & K-net & + & \\
\hline OKY015 & 53 & + & + & + & K-net & + & \\
\hline
\end{tabular}

${ }^{\mathrm{a}} \mathrm{A}$ plus indicates the record has been used in this study and a minus indicates that it was not used.

The time window used in the inversion is $60 \mathrm{~s}$ for all records. Both data and synthetics were normalized by the peak amplitude of the data to avoid giving too much weight in the inversion to the records with the largest amplitudes [e.g., Hartzell and Heaton, 1983; Cotton and Campillo, 1995].

\subsection{Geodetic Data}

[13] The geodetic data available for the 2000 Tottori earthquake consist of coseismic GPS measurements in the form of displacement vectors for GPS sites and leveling surveys around the focal region [Sagiya et al., 2002]. These data were collected by the Japanese nationwide continuous GPS observation network. Only the coseismic displacement vectors are used for the inversion. The measurements were made by differencing locations measured several weeks prior to the earthquake and about 2 months after the earthquake. The maximum displacement $(\sim 17 \mathrm{~cm})$ was observed south of the epicenter. The 14 closest stations associated with significant displacement have been selected in the inversion process. Figure 1 shows the selected GPS stations and the observed horizontal displacement vectors.

\section{Waveform Inversion Methodology}

\subsection{Inversion Method}

[14] A nonexhaustive list of inversion methods to study the rupture history developed during the last two decades includes those by Olson and Apsel [1982], Hartzell and Heaton [1983], Takeo [1987], Beroza and Spudich [1988], Olson and Anderson [1988], Mendoza and Hartzell [1988a, 1988b, 1989], Das and Kostrov [1990, 1994], Hartzell et al. [1991], Hartzell and Liu [1995, 1996], Cotton and Campillo [1995], Sekiguchi et al. [2000], Ji et al. [2002], and Liu and Archuleta [2004]. As discussed by Olson and Apsel [1982], Beroza and Spudich [1988], and Das and Kostrov [1990], in some cases, more than one slip model distribution can fit the

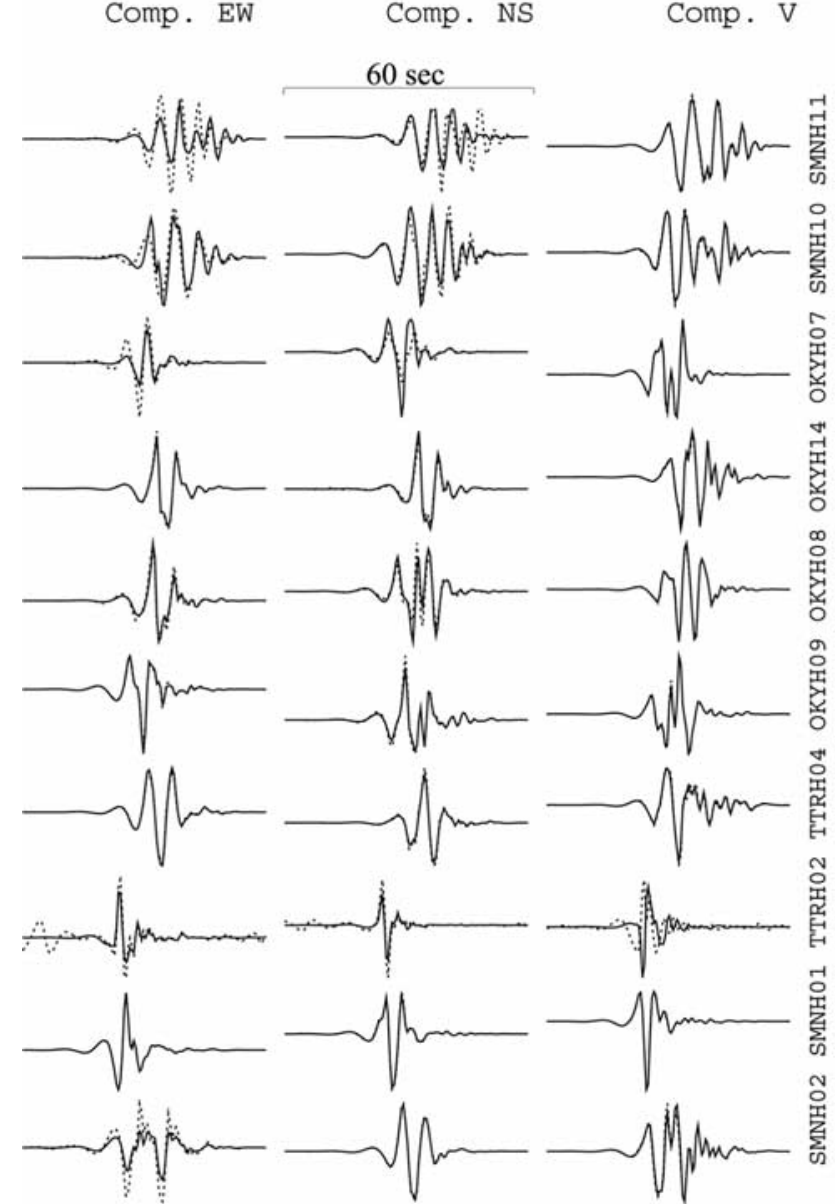

Figure 2. Displacement seismograms recorded at the surface (dashed), in boreholes (solid), and band passed in the frequency range $0.1-1.0 \mathrm{~Hz}$. Note that, in particular, horizontal components of TTRH02 are not usable after a double integration. 
data, which leads to different stress accumulation patterns and histories on the fault. The linearized frequency domain inversion method was described in detail by Cotton and Campillo [1995] and Hernandez et al. [1999]. We recall briefly the essential points of the method. The fault plane is divided into small subfaults. Each subfault is itself composed of several point sources equally distributed over the subfault. The Green functions for a layered velocity model are calculated numerically between each point source and each station and then linearly combined into the displacement due to a subfault where rupture propagates at a prescribed velocity. For each subfault, we allocate a source time function, which corresponds to a ramp function in slip (Figure 3). The local slip is characterized through three parameters: the start time of the rupture, the risetime, and the slip amplitude. With this parameterization, the ground displacement $V$ at $i$ th station and a given frequency, $\omega$, can be represented as a linear sum of $n$ subfault contributions, with given slip amplitude and duration, each one appropriately delayed in time to account for rupture propagation:

$$
\begin{gathered}
V_{i}(\omega)=\sum_{k=1}^{n} \operatorname{slip}_{k} \exp \left[-i \omega t_{k}\right] u_{k i}(\omega) S_{k}\left[\tau_{k}, \omega\right], \\
S(t)=0.5\{1+\tanh [(t+\tau / 2) /(\tau / 2)]\}
\end{gathered}
$$

where $u_{k i}$ represents the ground motion for a unit constant slip on the subfault $\mathrm{k}$ with a given source mechanism, $\omega$ is the angular frequency, $\operatorname{slip}_{k}, t_{k}$ and $S_{k}$ are the slip, the rupture time, and the source function of the $k$ th subfault, respectively. The latter depends on a single variable: the risetime $\tau_{k}$ (Figure 3 ). The analytical form of the source function $S$ is given by expression (2). This simple parameterization limits the number of model parameters with respect to the technique proposed by Olson and Anderson [1988]. For each subfault, the rupture time, the risetime and the slip amplitude are evaluated simultaneously using the spectral components of the records.

[15] We invert equation (1) by iterative minimization in the least squares sense [Tarantola and Valette, 1982]. Olson and Apsel [1982], Hartzell and Heaton [1983], Das and Kostrov [1990, 1994], and Hartzell and Liu [1995, 1996], among others, have identified physical and nonphysical constraints to limit oscillations in the solution. In this study we introduce three types of constraints: a positivity constraint (positive slip for all points on the fault for all times), allowing each subfault to slip only once and a smoothing constraint. Since our inversion is only able to reconstruct smooth models of the rupture process, we introduce a smoothing constraint to stabilize the solution. The smoothing constraint is introduced through the covariance matrix $C_{M}$ that describes the a priori information on the model parameters following Tarantola [1987]. The elements of the covariance matrix between a pair of $i$ th and $j$ th subfaults are given by

$$
C_{M, i j}=\sigma_{i} \sigma_{j} \exp \left(-\frac{1}{2} \frac{d_{i j}^{2}}{\Delta l^{2}}\right)
$$

$\sigma$ is the a priori model parameter variance (the variance is the same for all subfaults, $\left(\sigma_{i}=\sigma_{j}\right), d$ is the distance between
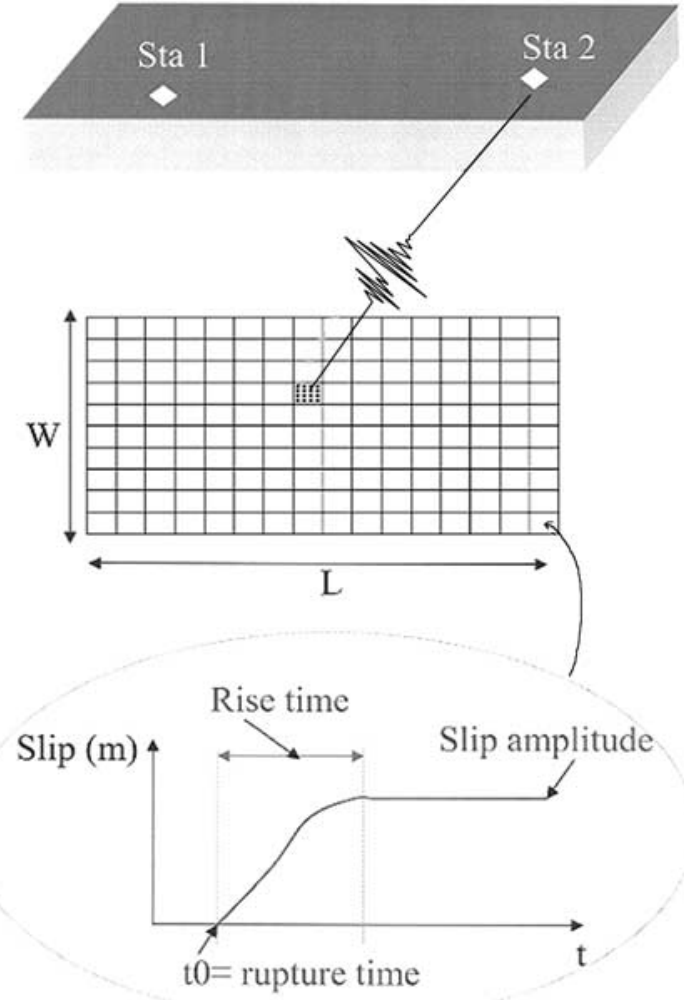

\section{Source time function}

Figure 3. Source parameterization. We divide the fault plane into small subfaults. Each subfault is represented by an array of point sources. The point source Green functions are calculated for a layered velocity model for each station. A smoothed ramp function in displacement is used for each subfault.

the two subfaults and $\Delta l$ is the correlation length. Note that no smoothing is introduced on the rupture time.

\subsection{Crustal Structure Model and Green's Functions}

[16] An elastic half-space is often used to model static deformation [e.g., Okada, 1985; Freymueller et al., 1994; Peltzer et al., 2001]. Cattin et al. [1999] studied the difference between inverted coseismic displacements for a vertical dip-slip fault using a layered half- space and a homogeneous half-space. In agreement with Savage [1998], they concluded that the resulting displacement could differ by $10-20 \%$. The horizontal displacements are more affected than the vertical ones. To avoid this overestimation, we used the same layered crustal model to calculate both static deformations and seismograms as already done by Hernandez et al. [1999]. The crustal velocity model is shown in Table 3. This model is used for the hypocenter determination by Research Center for Earthquake Prediction-Disaster Prevention Research Institute (RCEP-DPRI), Kyoto University. An attenuation coefficient for both $\mathrm{P}$ and $\mathrm{S}$ waves is added. All borehole stations used in this study are at about $100 \mathrm{~m}$ depth. Because the wavelength of the waves used in the inversion is greater than $500 \mathrm{~m}$, we calculate at each station only one Green's function for both sensors. The Green's functions used to calculate the strong motion 
Table 3. Velocity Structure

\begin{tabular}{cccccc}
\hline $\mathrm{h}, \mathrm{km}$ & $\mathrm{V}_{\mathrm{p}}, \mathrm{km} / \mathrm{s}$ & $\mathrm{V}_{\mathrm{s}}, \mathrm{km} / \mathrm{s}$ & $\mathrm{d}, \mathrm{kg} / \mathrm{m}^{3}$ & $\mathrm{Q}_{\mathrm{p}}$ & $\mathrm{Q}_{\mathrm{s}}$ \\
\hline 0 & 5.50 & 3.179 & 2600 & 500 & 200 \\
2 & 6.05 & 3.497 & 2700 & 500 & 200 \\
16 & 6.60 & 3.815 & 2800 & 500 & 200 \\
38 & 8.03 & 4.624 & 3100 & 500 & 200 \\
\hline
\end{tabular}

synthetics are computed numerically for the layered velocity model described in Table 3, using AXITRA computer package [Coutant, 1989].

\subsection{Origin time}

[17] In several recent cases it has been observed that the beginning of major slip is preceded a few seconds by a foreshock. This observation has been interpreted to be related to the initiation phase of sliding before the propagation phase of rupture [Iio, 1992; Ellsworth and Beroza, 1995; Campillo and Ionescu, 1997]. For example, such phenomena were reported for the following events: Landers, 1992 [Campillo and Archuleta, 1993], Hector Mine, 1999 [Ji et al., 2002]; and Sanriku-Haruka-Oki, 1994 [Nakayama and Takeo, 1997]. In the case of the 2000 Tottori earthquake, the beginning of major slip began several seconds after a first break. In our study we adopt the origin time given by Iwata and Sekiguchi [2002] (Table 1).

\section{Results}

\subsection{Fault Plane Geometry Selection}

[18] For our starting models we first adopted the fault geometry used by Iwata and Sekiguchi [2002], i.e., a fault plane with strike $\mathrm{N} 150^{\circ} \mathrm{E}$ and dip $90^{\circ}$. The dimensions are set to a length of $32 \mathrm{~km}$ and a depth of $20 \mathrm{~km}$. We consider two discretizations, one with large subfaults of size $4 \mathrm{~km} \times$ $4 \mathrm{~km}$ (the hypocenter is located at a depth of $14 \mathrm{~km}$ ) and the other with small subfaults of size $2 \mathrm{~km} \times 2 \mathrm{~km}$ (the hypocenter is located at a depth of $15 \mathrm{~km}$ for convenience).

[19] We observed that the synthetics do not fit the record at the nearest station (TTRH02, located east of the $\mathrm{N} 150^{\circ}$ fault plane) with the geometry defined by Iwata and Sekiguchi [2002]. On the opposite side at station SMNH01, which is almost at the same distance, we obtained a good agreement. This observation suggests a mislocation of the fault plane with respect to TTRH02. We therefore consider a possible change of strike in the southern part of the fault. Figure 4 presents the comparison between the $150^{\circ}$ and $146^{\circ}$ strikes for the southern part of the fault. The N-S component is discriminant and shows that the $146^{\circ}$ strike for which station TTRH02 is located west of the fault plane is in agreement with the observed ground motion. The aftershocks plotted in Figure 1 are relocated by Fukuyama et al. [2003] using the high-resolution technique developed by Waldhauser and Ellsworth [2000]. We observe a good agreement between our two fault plane segments directions and the relocated seismicity. This geometry is finally used in our study.

\subsection{GPS Inversion}

[20] The geodetic displacements are calculated in the same layered velocity structure used in computing the strong motion waveforms (Table 3). The observed coseismic displacement vectors are displayed with arrows in Figure 1. On Figure 1, the coseismic deformation pattern clearly shows left lateral strike slip motion. For the GPS data inversion, we used an initial model which consists of two vertical fault plane segments (Figure 4). The length along strike is $32 \mathrm{~km}$ and $20 \mathrm{~km}$ along dip. We discretized the fault plane into a total of 40 large subfaults $(4 \mathrm{~km} \times$ $4 \mathrm{~km})$ or 160 small subfaults $(2 \mathrm{~km} \times 2 \mathrm{~km})$. A constant initial slip of $35 \mathrm{~cm}$ is used for each subfault. Knowing that surface static displacement is mostly sensitive to the shallow part of the fault [Hernandez et al., 1999], the details of the slip distribution at depth cannot be resolved.

[21] The spatial distribution of slip obtained from inversion of geodetic data is given in Figure 5a. In Figure 5b, synthetic horizontal displacement field (gray) are compared with the observed GPS data (black). The maximum strike slip at $2-3 \mathrm{~km}$ depth is about $170 \mathrm{~cm}$ and extends over about $6 \mathrm{~km}$. The total seismic moment deduced from the slip distribution is $13.8 \times 10^{18} \mathrm{~N} \mathrm{~m}\left(M_{w}=6.73\right)$. This result is discussed later.

\subsection{Strong Motion Inversion}

[22] We tested a range of initial models with constant rupture velocity, risetime, and slip. Table 4 shows the misfits obtained for different initial models. We tried a range of values of velocity from 2500 to $3000 \mathrm{~m} / \mathrm{s}$ and risetimes between 0.9 and $2.7 \mathrm{~s}$. For these inversions we used large subfaults $(4 \mathrm{~km} \times 4 \mathrm{~km})$ and the set of strong motion borehole records. We found the best variance reduction when taking an initial model with a rupture velocity of $2800 \mathrm{~m} / \mathrm{s}$ and a risetime of $1.2 \mathrm{~s}$.

\subsubsection{Data and Subfaults Size Choices \\ 4.3.1.1. Borehole Records and Subfault Parameterization}

[23] Hartzell and Langer [1993] and Das and Suhadolc [1996] have pointed out some examples of the significant effects on a finite fault inversion that are produced by changes in model parameters such as subfault size. The slip distribution obtained using borehole records and large subfaults is displayed in Figure 6a. The maximum slip equals $230 \mathrm{~cm}$. The total moment estimate is $15.5 \times$ $10^{18} \mathrm{~N} \mathrm{~m}$, equivalent to a moment magnitude of 6.76 .

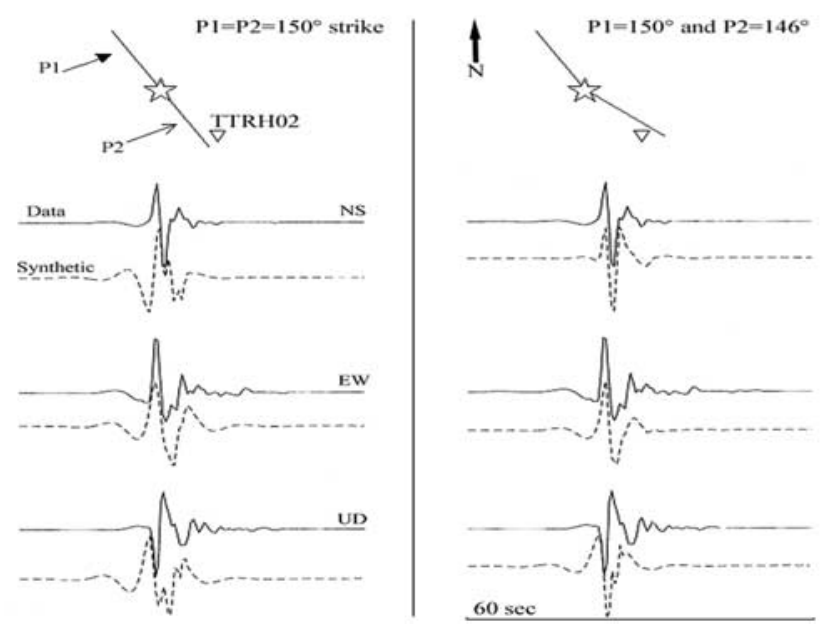

Figure 4. Fit between data (solid) and synthetics (dashed) at station TTRH02. These tests show that the fault plane is located east of station TTRH02. 

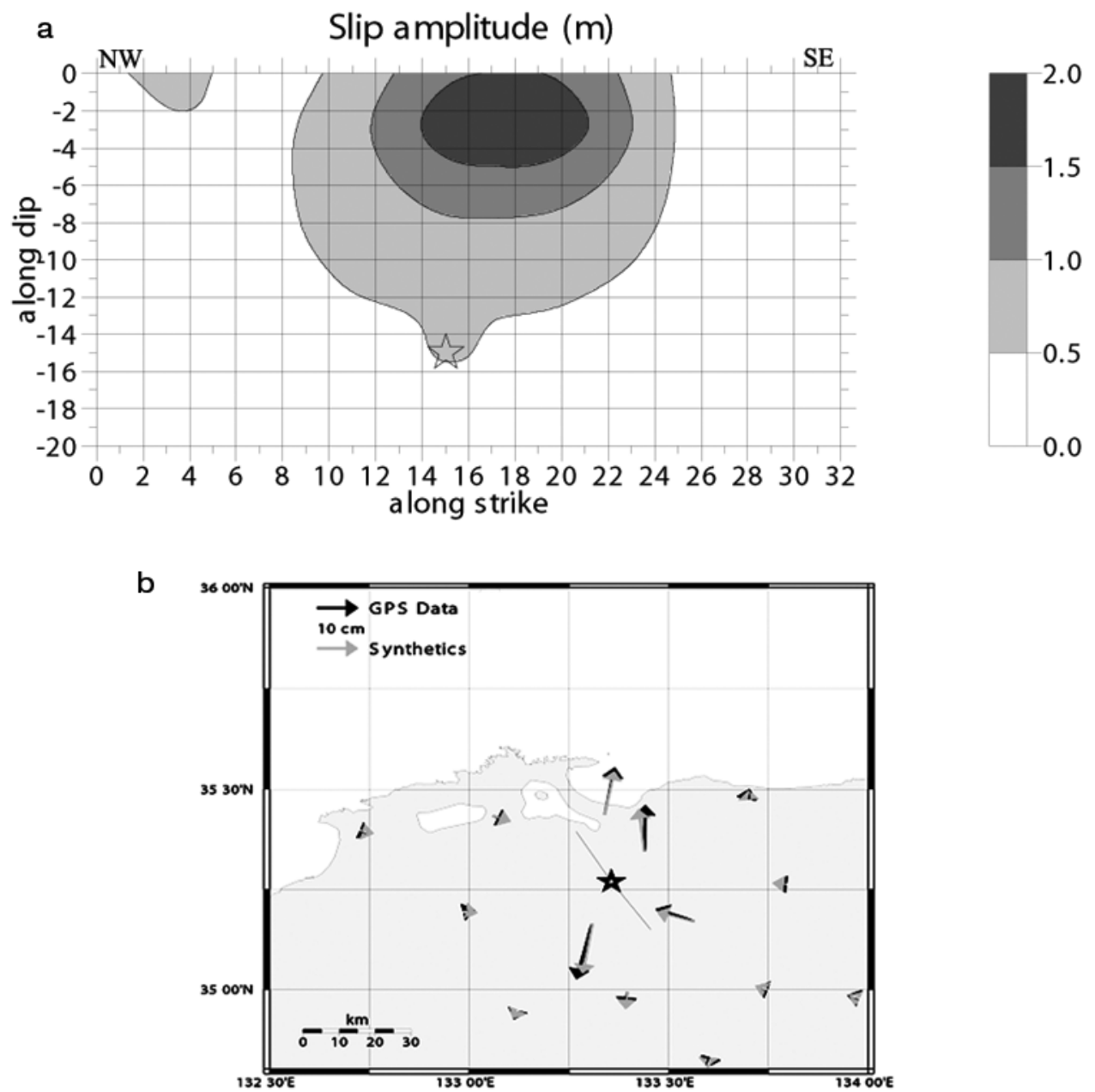

Figure 5. (a) Slip distribution model using the least squares inversion scheme for GPS data. The best fault model geometry described in Figure 4 (right) is used with an initial $35 \mathrm{~cm}$ slip on each subfault. The final seismic moment is $13.8 \times 10^{18} \mathrm{~N} \mathrm{~m}\left(M_{w}=6.73\right)$. (b) Comparison between data (black vector) and synthetic (gray vector) after a direct modeling.

The variance reduction is about $68 \%$. While the slip distribution (Figure $6 a$ ) is rougher than the one obtained from GPS data (Figure 5a), we observe in both cases a large asperity in the same region of the fault plane. Note that in order to compare this model with the model obtained using surface data, station TTRH02 is ignored since it is not in the surface record data set, due to instrumental problem (see Figure 2).

[24] Figure $6 \mathrm{~b}$ presents the model obtained with small $2 \times$ $2 \mathrm{~km}^{2}$ subfaults, and borehole records. It shows that the single asperity found in the large subfault model between 0 and $8 \mathrm{~km}$ depth and 6 and $24 \mathrm{~km}$ in the strike direction is in fact a fusion of several asperities of smaller size. The seismic moment associated with the small subfaults solution is $14.4 \times 10^{18} \mathrm{~N} \mathrm{~m}\left(M_{w}=6.74\right)$, very close to the one obtained for larger subfaults. The variance reduction is about $70 \%$. The maximum slip is $280 \mathrm{~cm}$. The slip distribution at the top of the fault is not the same for the large subfault or small subfault models.

\subsubsection{Surface Data Records and Subfault \\ Parameterization}

[25] Until now only borehole records have been used. Figure $6 \mathrm{c}$ shows the slip model obtained using surface records in the case of the large subfault model. We notice that compared with the solution derived from borehole records (Figure 6a), the maximum slip amplitude occupies a slightly smaller area, but in general the form of the asperity is the same. The maximum slip amplitude is $207 \mathrm{~cm}$ and the moment magnitude does not change. On the other hand, the variance reduction is about $62 \%$ (less than the variance reduction obtained with borehole records) the difference is probably due to site effects that are not considered in our direct problem but are important at some KIK-net stations.

[26] A similar test performed with the small subfault parameterization is presented on Figure $6 \mathrm{~d}$. It must be

Table 4. Summary of Inversion Set

\begin{tabular}{ccc}
\hline Rupture Velocity, m/s & Risetime, s & Variance Reduction, $\%$ \\
\hline 2500 & 1.2 & 63.16 \\
2700 & 1.2 & 65.10 \\
2800 & 1.2 & 65.34 \\
2900 & 1.2 & 64.72 \\
3000 & 1.2 & 62.72 \\
2800 & 2.7 & 62.96 \\
2800 & 2.2 & 64.59 \\
2800 & 1.7 & 61.95 \\
2800 & 1.2 & 65.34 \\
2800 & 0.9 & 64.90 \\
\hline
\end{tabular}


a / Strong motion alone. Large subfaults (downhole records=DR): Mw6.76; var. red. $=67.7 ;$ max. slip $a m p .=230 \mathrm{~cm}$.

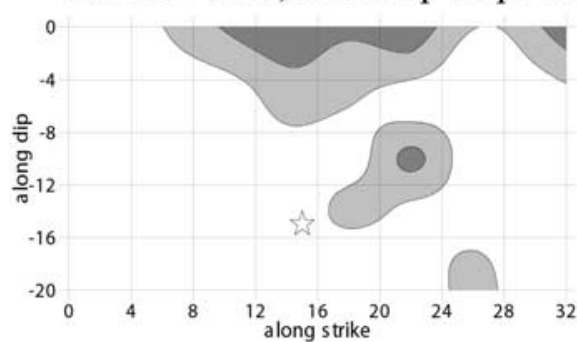

c / Strong motion alone. Large subfaults (surface records $=$ SR): Mw6.76; var. red. $=61.9 ;$ max. slip amp. $=207 \mathrm{~cm}$

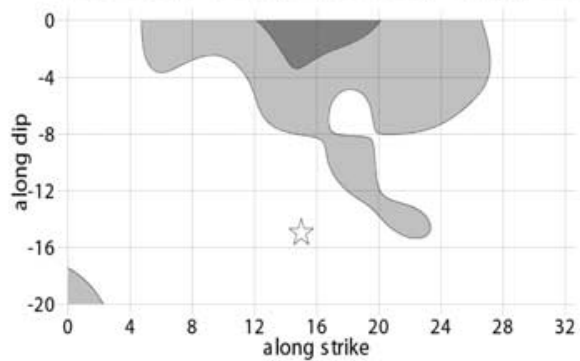

e / Two-step inversion model (DR): Mw6.79; var. red. $=69.39$; max. slip amp. $=303 \mathrm{~cm}$.

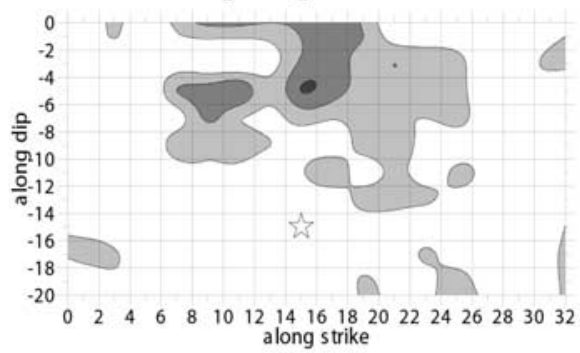

$\mathrm{g} / 2$-step inversion model with smoothing $(\mathrm{xl}=2 \mathrm{~km})$ : var. red. $=68.24 \% ; \mathrm{Mw}=6.79$; max. slip $=313 \mathrm{~cm}$.

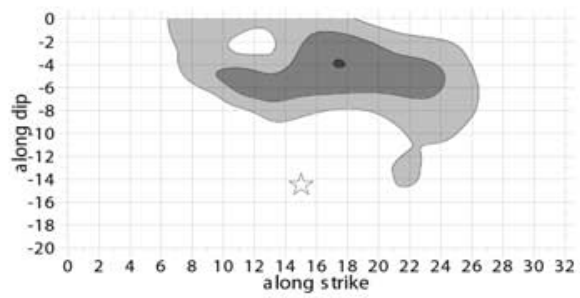

b/ Strong motion alone. Small subfaults

(DR): Mw6.74; var. red. $=70 \%$;

max. slip amp. $=279 \mathrm{~cm}$.

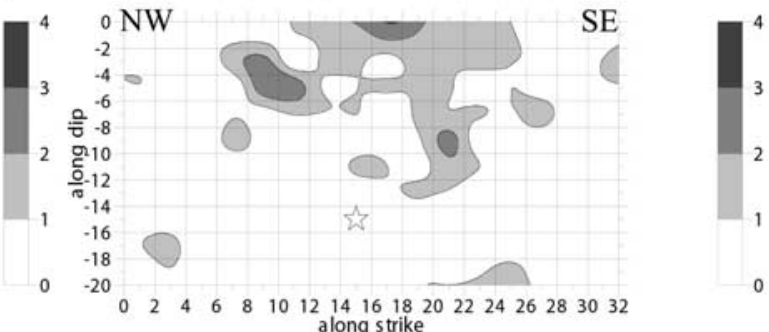

d / Strong motion alone. Small subfaults (SR): Mw6.74; var. red. $=64.20$;

max. slip amp. $=375 \mathrm{~cm}$.

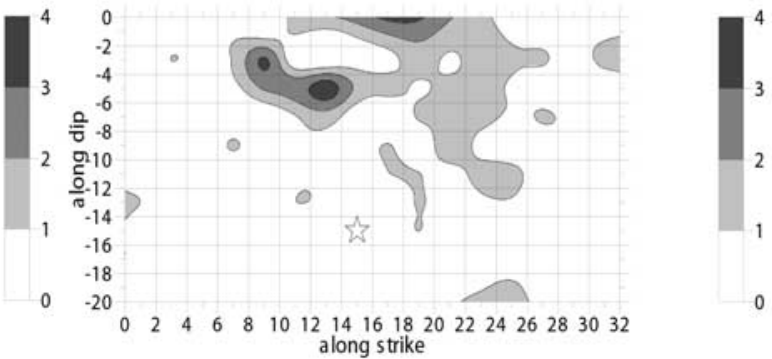

f / 2-step inversion model with smoothing $(\mathrm{xl}=1 \mathrm{~km})$, var. red. $=69.05 \% ; \mathrm{Mw}=6.79$; max. slip=301 cm.

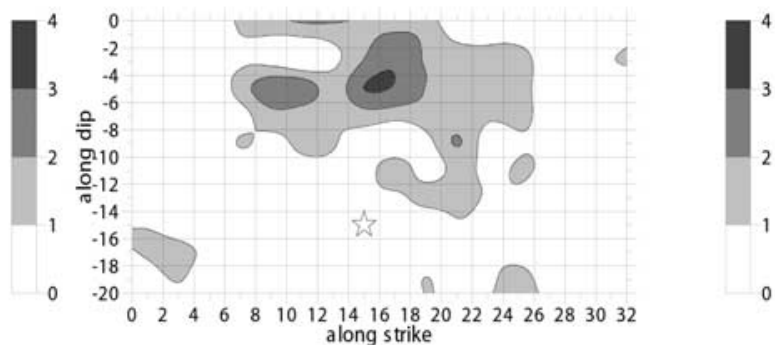

h / Fault plane at $2 \mathrm{~km}$ depth: 2-step inversion model. Mw6.77; var.red. $=67 \%$; max slip350 $\mathrm{cm}$.

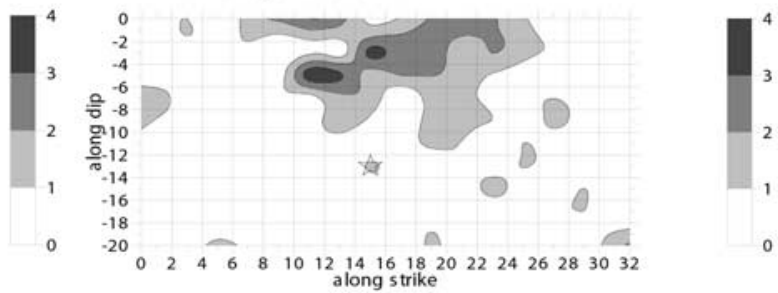

Figure 6. Different slip distribution models derived in this study. Contour interval is $1 \mathrm{~m}$. Top left corner is the NW direction, and top right corner is the SE direction. Star is the hypocenter.

compared with the results obtained with borehole records on Figure 6b. The global shape of the asperity is the same but again the maximum slip amplitude is greater $(375 \mathrm{~cm})$. The seismic moment is very similar to the one inferred from borehole records $\left(M_{w}=6.74\right)$. Note that the use of contaminated surface data in this study slightly decreases the variance reduction (about 2-6\%). Consequently, for the following final inversion runs we will use only borehole records and small subfault parameterization. 


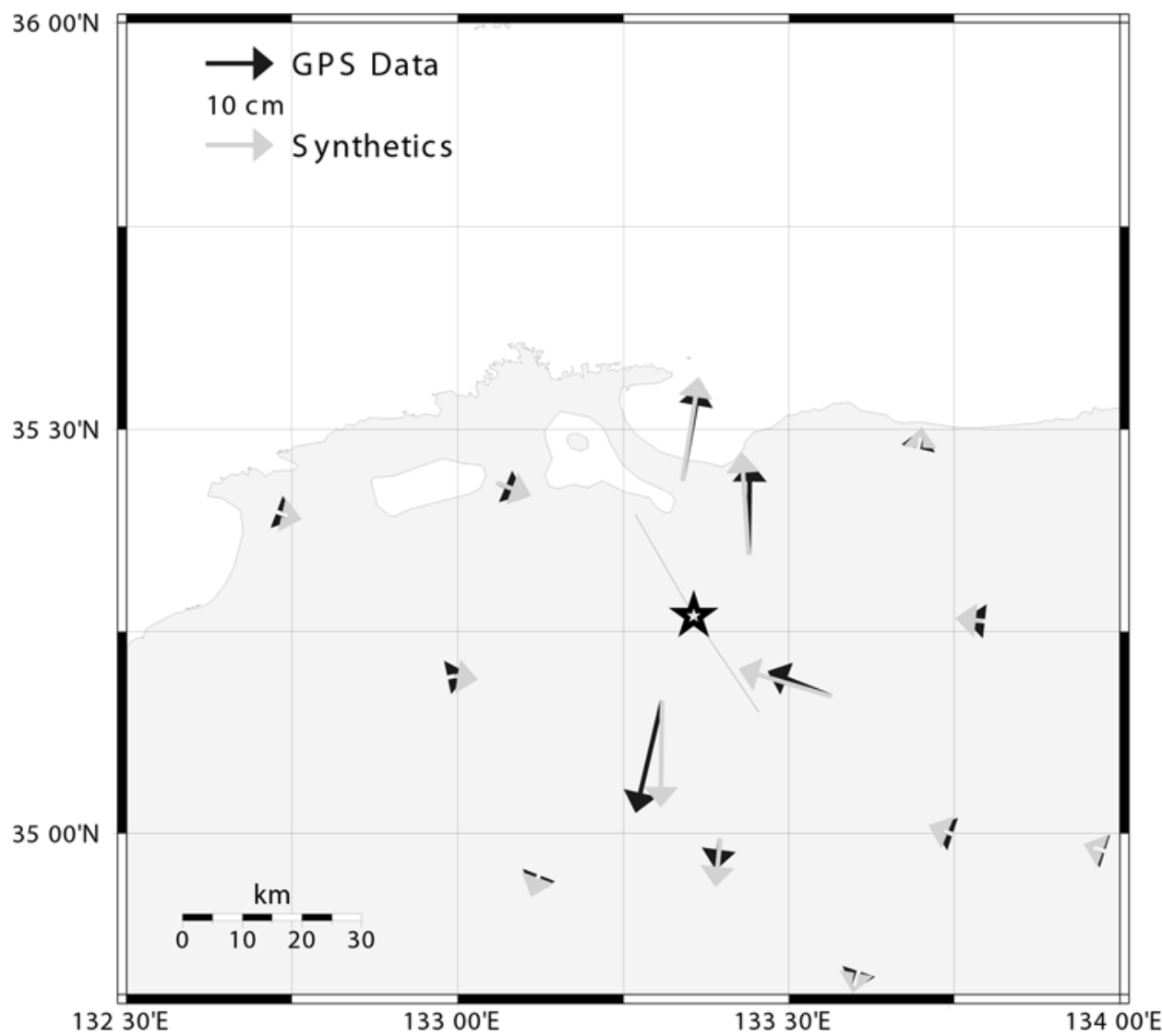

Figure 7. Observed (black) GPS data. Synthetics (gray) GPS horizontal vector displacement calculated using as input for the direct modeling the two-step inverted model with fault plane at $0.5 \mathrm{~km}$ depth.

\subsection{Two-Step Inversion With Slip Allowed at the Surface}

[27] To improve the quality of the inversion, Hernandez et al. [1999] proposed to use a two-step inversion. It uses the information obtained from the inversion of geodetic data (slip distribution and uncertainties) to build an a priori model for the strong motion inversion. We applied the two step inversion without a priori smoothing constraint to borehole records.

[28] The slip distribution is presented in Figure 6e. The variance reduction is $69.4 \%$. The solution obtained has a large asperity with a maximum amplitude of slip equal to $303 \mathrm{~cm}$ located above the hypocenter at about $5 \mathrm{~km}$ depth. This model yields a seismic moment of $1.7 \times 10^{19} \mathrm{~N} \mathrm{~m}$ corresponding to a moment magnitude of 6.79 . Note that applying a $1000 \mathrm{~m}$ correlation length smoothing reduces the slip at the top of the fault from about $3 \mathrm{~m}$ to about $2 \mathrm{~m}$ (Figure 6f) and the shape of the asperity does not change. Applying a $2 \mathrm{~km}$ correlation length smoothing (Figure 6g), the maximum slip lies on a larger area and the variance reduction slightly decreases. The moment magnitude does not change.

\subsection{Two-Step Inversion Model With No Slip at the Surface}

[29] The two-step inversion with a fault reaching the surface results in large slip (larger than $2 \mathrm{~m}$ ) for the shallow subfaults. This shallow slip is not in agreement with geological observations, which indicate that slip did not reach the surface. In order to constrain the depth of the rupture top, we performed a two-step inversion where the fault model is shifted downward by $2 \mathrm{~km}$, keeping constant the number of parameters. The result of the GPS data inversion (first step) shows one large asperity located above the hypocenter, in agreement with the result in Figure 5a. This slip model is then used to invert strong motion records (second step). The results are shown in Figure $6 \mathrm{~h}$. The peak slip is $350 \mathrm{~cm}$. The variance reduction is about $67 \%$, which is slightly less than the one associated to the previous model (with a shallower slip). The seismic moment is $15.9 \times 10^{18} \mathrm{~N} \mathrm{~m}$ corresponding to $M_{w}=6.77$. We performed two other inversions giving different depths to the fault top $(1 \mathrm{~km}$, $0.5 \mathrm{~km})$. Shallow faults show the highest variance reduction. These tests confirm that slip actually occurred at very shallow depths. We therefore consider the fault with top at $0.5 \mathrm{~km}$ our preferred model since it is in agreement simultaneously with geodetic and seismological data and also geological observations. The fit between the synthetics generated by this model (a two-step inverted model) and the GPS observed data is shown in Figure 7.

[30] Figure 8 is a comparison of the observed and the calculated strong motions using the model with fault plane top at $0.5 \mathrm{~km}$ depth. In general the waveforms are well matched (68.2\% variance reduction). In Figure 9 we 
Comp.EW

Comp. NS

Comp. V
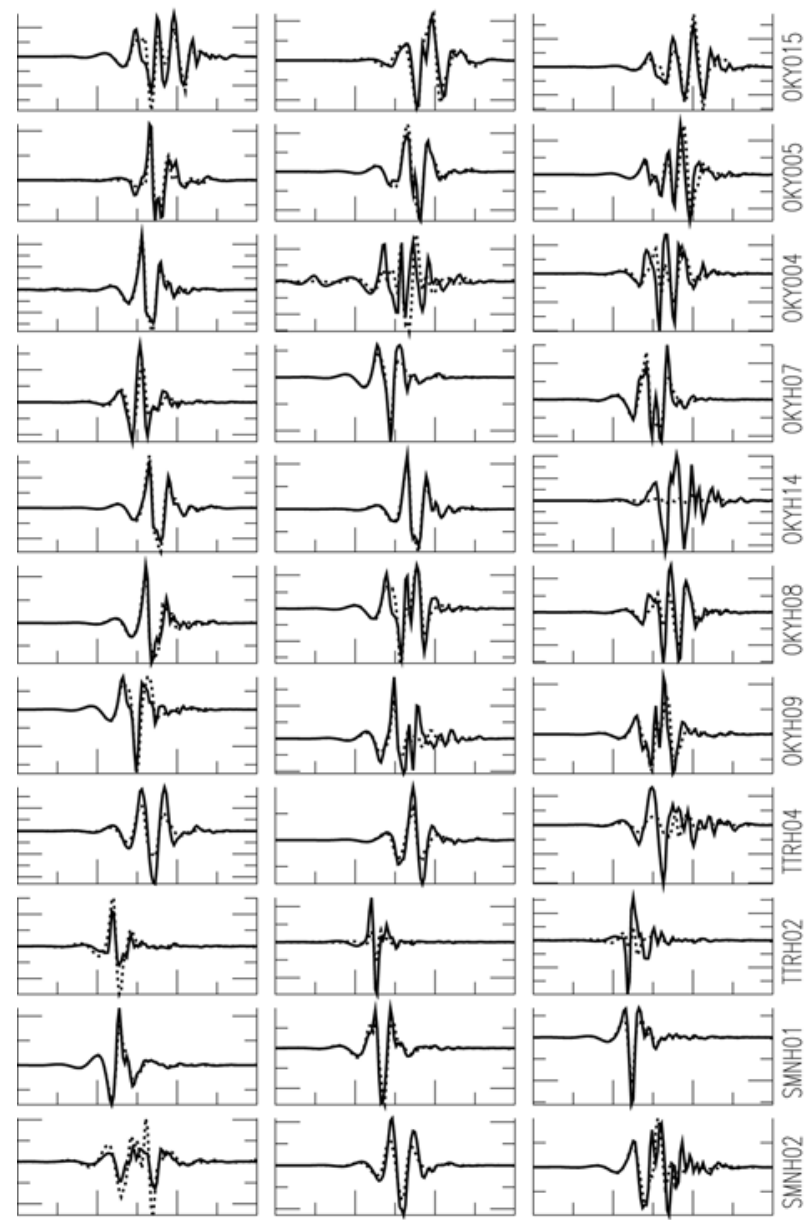

Comp.NS

Comp.V
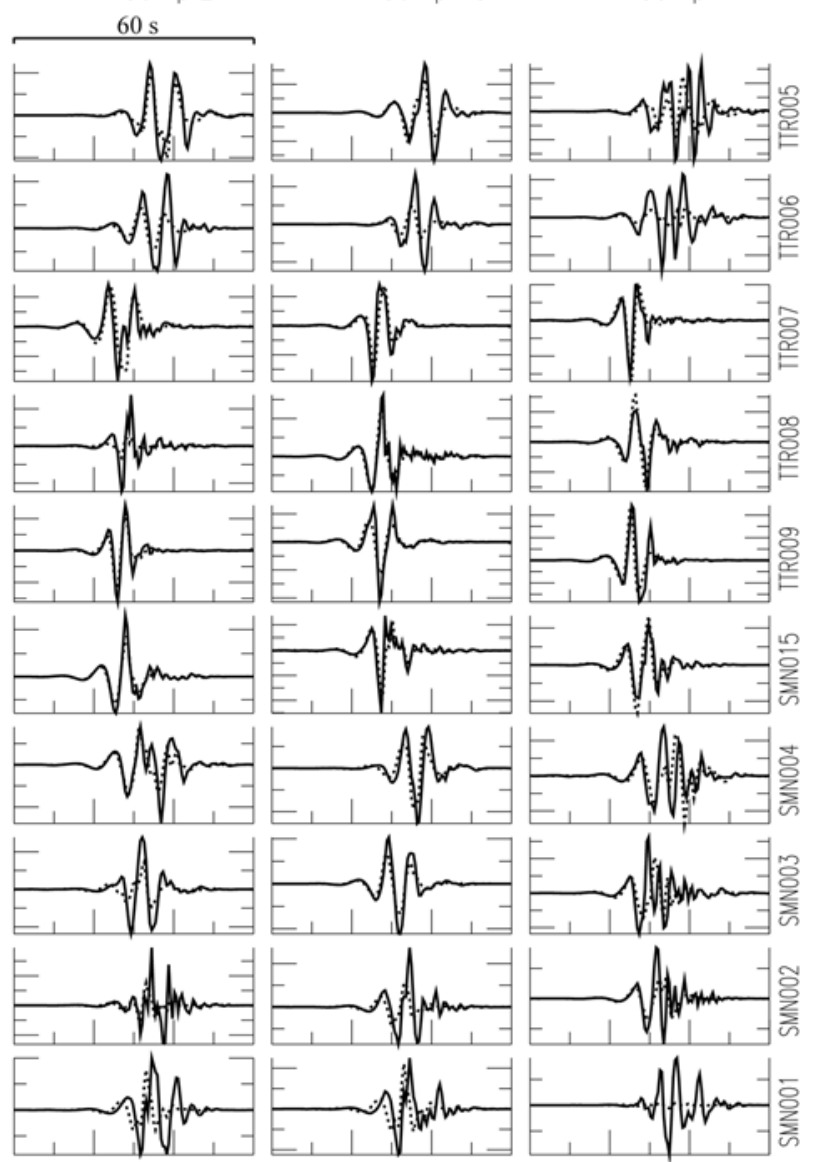

Figure 8. Observed (solid line) and synthetic (dashed line) strong motion records. Original acceleration waveforms are band passed in the frequency range $0.1-1.0 \mathrm{~Hz}$ using a two-pole Butterworth filter applied forward and backward then doubly integrated to obtain the particle displacement. The vertical components of some strong ground motion are not used in the inversion (see Table 1) because of incomplete knowledge of the seismic velocity structure. All components (synthetics and observed) at each station are normalized with the data peak amplitude. Each pair of observed and calculated seismograms is plotted at the same amplitude scale.

plotted for each frequency the variance reduction between data and synthetics for all the stations. The fit in the frequency range $[0.1-0.3] \mathrm{Hz}$ exceeds $40 \%$, and over the range $0.3-0.5 \mathrm{~Hz}$ it is greater than $30 \%$. Figure 9 indicates the limited frequency band in which the rupture model is actually resolved. We interpret the upper frequency limit as the limit of applicability of the simplified layered crustal model employed to calculate the Green's functions.

[31] The result of the three inverted parameters (slip amplitude, rupture time, and risetime) of our preferred model (at $0.5 \mathrm{~km}$ depth) is shown in Figure 10, and the evolution of rupture is displayed in Figure 11. The main asperity breaks $1 \mathrm{~s}$ after the first break in the north direction then grows first upward and then parallel to the Earth's surface. The total rupture duration is about $8 \mathrm{~s}$. Figure 11 shows that the significant slip $(>1 \mathrm{~m})$ occurs away from the hypocenter and propagates laterally. The maximum of the

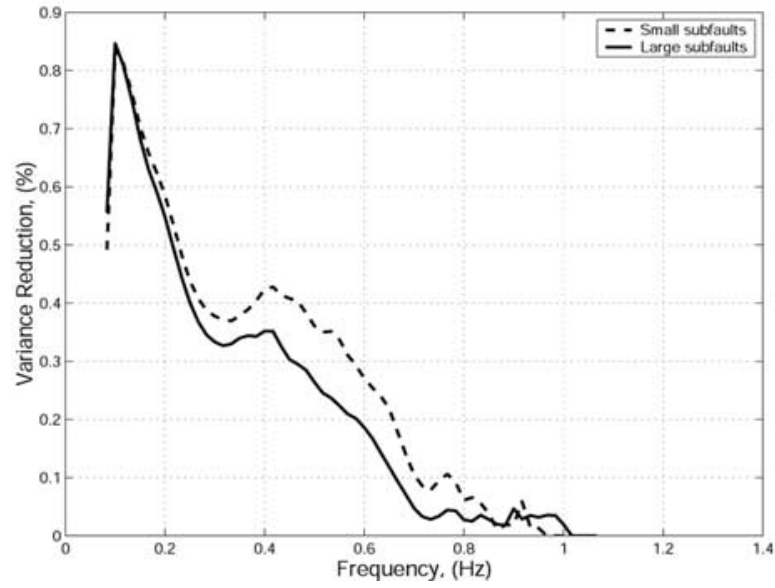

Figure 9. Variance reduction between data and synthetic computed for all the stations for each frequency. It is shown that the data are fitted on the frequency range $0.1-0.3 \mathrm{~Hz}$. 

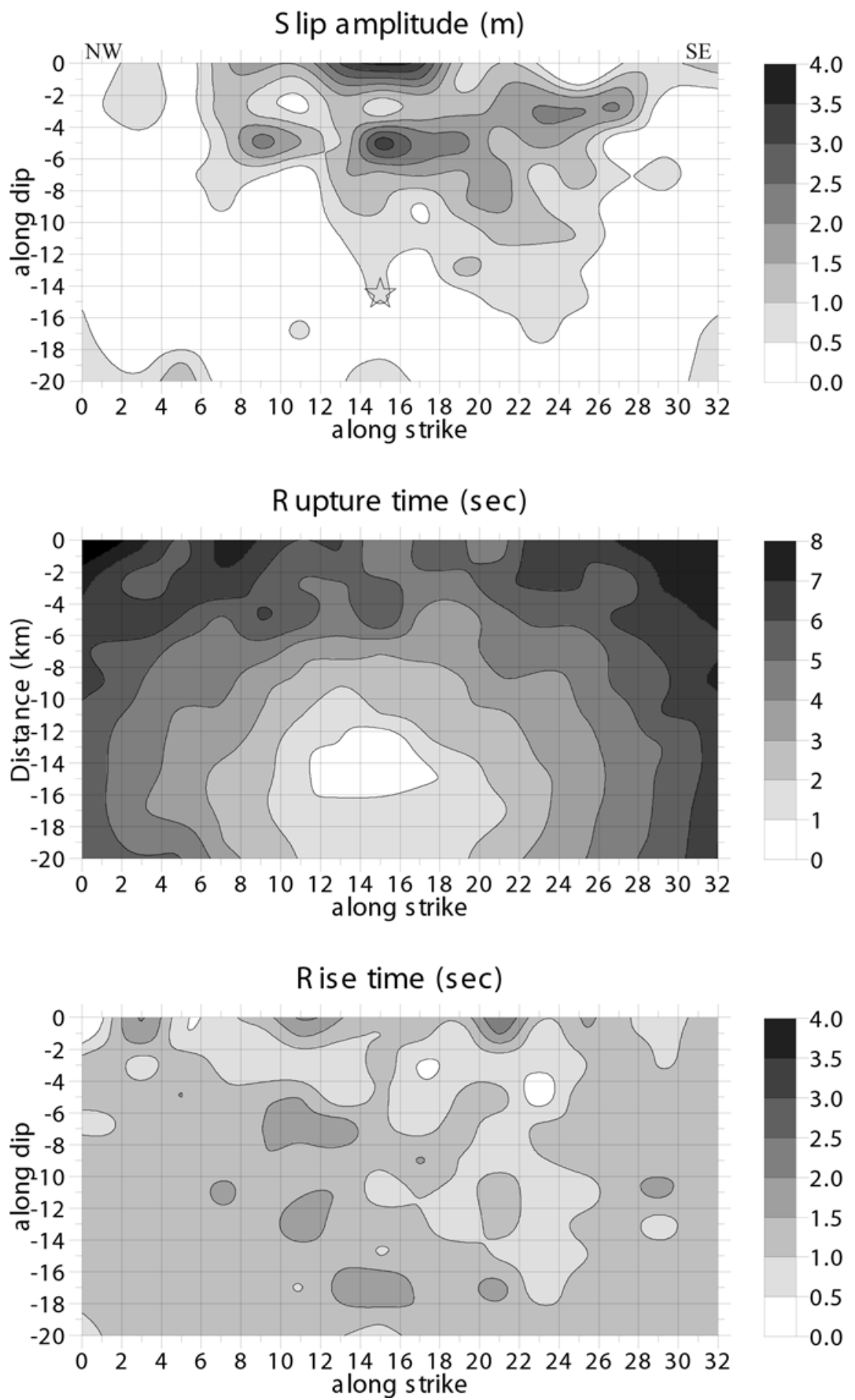

Figure 10. Three parameters inversion results using the geometry fault shown in Figure 4 (right) and borehole records. (top) Recovered slip distribution on the fault plane, (middle) rupture front evolution, and (bottom) slip duration.

slip takes place at about $5 \mathrm{~km}$ depth. During the earthquake, the region at depth, west of the hypocenter does not slip.

\section{Discussion and Conclusions}

[32] Uncertainties exist in kinematic source models deduced from inversions but these are difficult to quantify since they have a variety of origins (e.g., model parameterization, data weighting, and inversion procedure). The knowledge of the nonuniqueness in kinematic parameters is important because these kinematic solutions are often used to determine the dynamic source parameters of earthquakes (i.e., stress drop and strength distribution) and for prediction of strong ground motion. In our study we have 

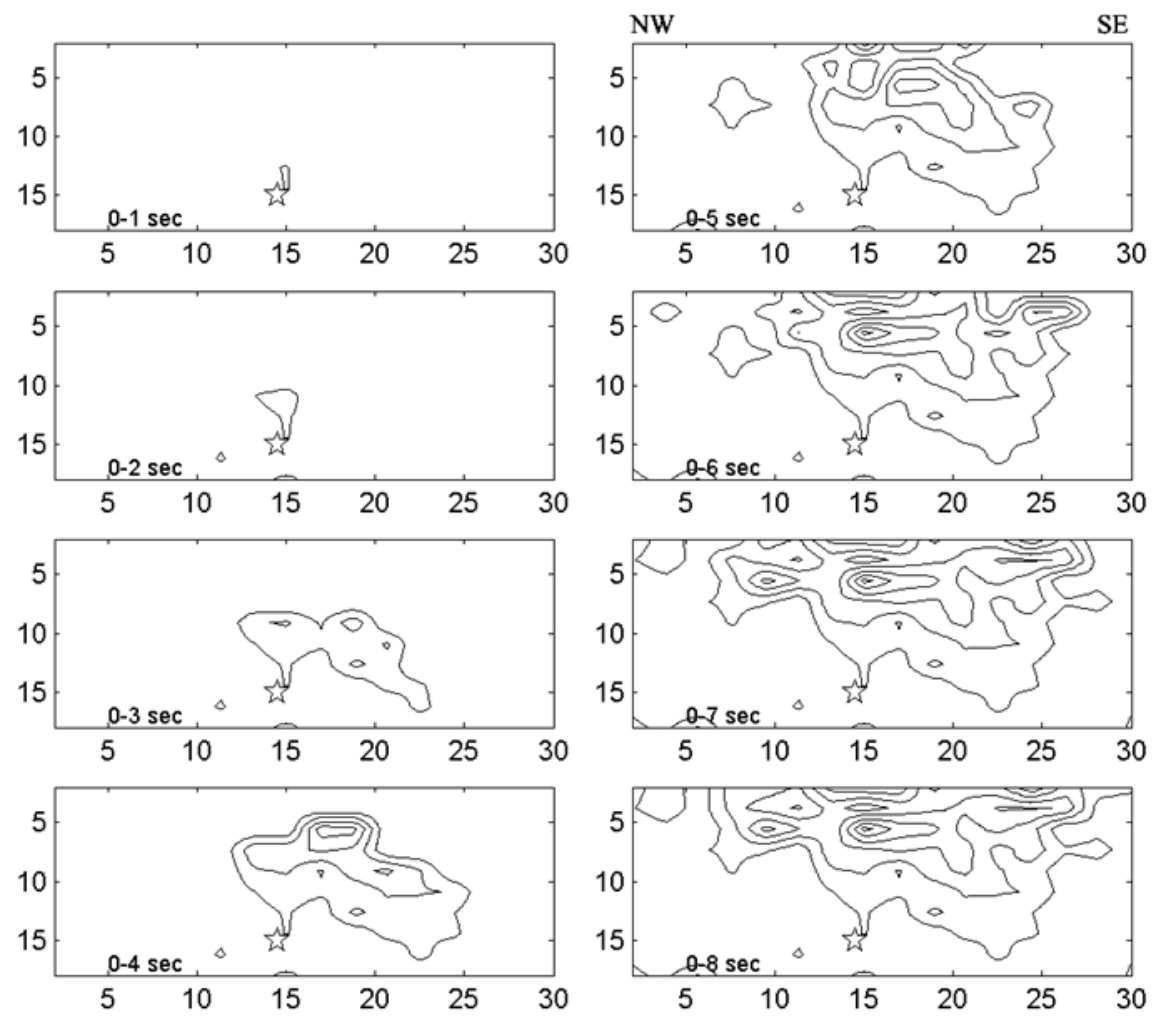

Figure 11. Spatiotemporal slip evolution of the preferred rupture model. Contour intervals are equal to $0.5 \mathrm{~m}$.

used borehole and surface records of KIK-net network to compare borehole with surface ground motions. At some stations there is a significant difference between the two records. We noticed that, systematically the variance reduction decreases using surface data, the general shape of the mean asperity remains unchanged, and the seismic moment also does not change significantly.

[33] The maximum slip amplitude and its position change whether using small or large subfaults. The one-block asperity at the vertical of the hypocenter, found with large subfault model, consists of a merger of several small asperities of comparable slip amplitude revealed when using small size subfault parameterization.

[34] For earthquakes occurring on hidden faults, it is possible to determine the location and orientation of the fault plane using the 3-D aftershock distribution. Seismological stations close to the rupture area also help to better constrain the fault plane orientation. We have seen in this study how change in the strike direction of the southern part of the fault plane strongly affects the fit at station TTRH02.

[35] The slip distributions we obtain agree with those of Iwata and Sekiguchi [2002] and Y. Yagi and M. Kikuchi

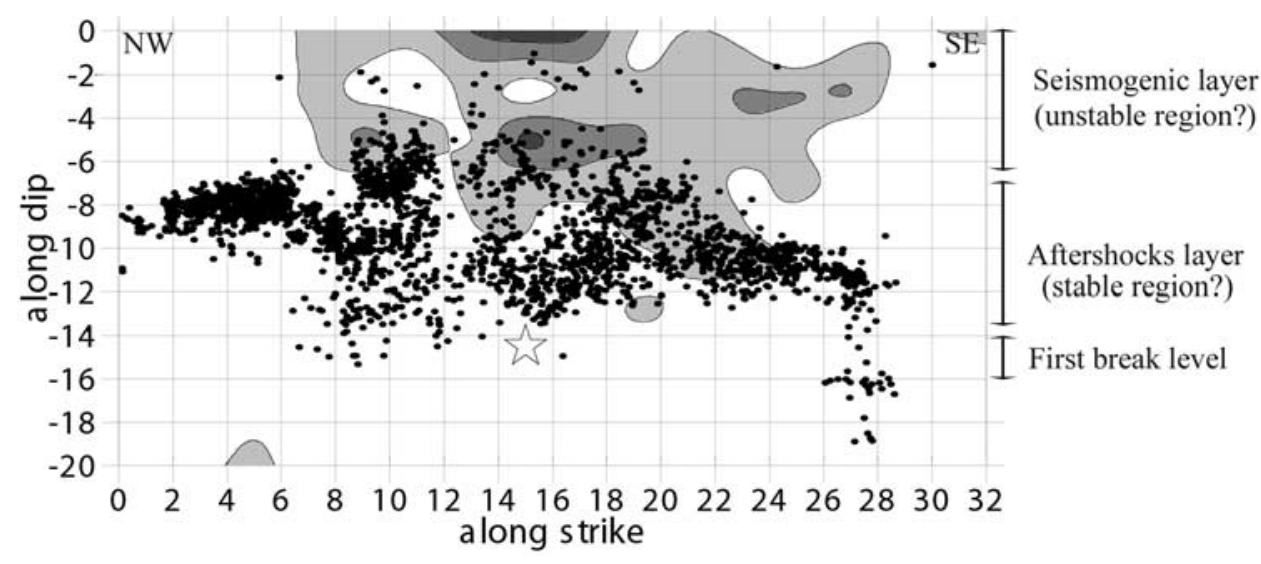

Figure 12. Relocated aftershocks ( $1 \mathrm{~km}$ on both sides of our fault plane) plotted over our slip map. The contour interval for the slip distribution is $1.0 \mathrm{~m}$. The star indicates the main shock hypocenter. The perpendicular plan (NW of epicenter) highlighted by the aftershocks distribution (see Figure 1) could play a role in stopping the rupture propagation. 
Table 5. Slip Model Properties Comparison

\begin{tabular}{lcc}
\hline \multicolumn{1}{c}{ Parameters } & Somerville et al. $[1999]^{\mathrm{a}}$ & This Study \\
\hline Risetime, $\mathrm{s}$ & 1.4 & 1.2 \\
Average slip, cm & 75 & 62 \\
Largest asperity, $\mathrm{km}^{2}$ & 102 & 108 \\
\hline
\end{tabular}

${ }^{\text {a}}$ With a moment of about $1.5 \times 10^{19} \mathrm{~N} \mathrm{~m}$.

(Source rupture process of the Tottori-ken Seibu earthquake of Oct. 6, 2000, unpublished manuscript, 2000) even though the fault parameterization and inversion schemes are very different. All three models show that slip propagated in the SE direction from the epicenter. We selected the relocated aftershocks of Fukuyama et al. [2003] (in a $1 \mathrm{~km}$ band width on both sides of the fault plane) and plotted them on our slip map (Figure 12). The majority of aftershocks occurred in the middle of the fault at about $6-12 \mathrm{~km}$ depth. This suggests that the region between the hypocenter and the large asperity sustained a high stress level without large coseismic slip. Numerical experiments done by Das and Aki [1977] and Mikumo and Miyatake [1978] showed that a rupture can propagate leaving behind it unbroken barriers [Aki, 1984]. A striking feature of Figure 12 is that the crust exhibits a depth-varying behavior. Failure begins at about $15 \mathrm{~km}$ depth. Then we find above the aftershocks (perhaps a barrier or a "stable" slip area), the asperity layer (seismogenic or unstable layer) and finally the superficial layer where neither slip (according to geological observations) nor aftershocks are observed. We report here two analogies between the 2000 Tottori and the 1979 Imperial Valley earthquakes: (1) Negative values of the dynamic stress drop near the free surface (Dalguer et al. [2002] for Tottori and Quin [1990] for Imperial Valley) and (2) the lack at shallow depth of microseismicity (Fukuyama et al. [2003] for Tottori and Doser and Kanamori [1986] and Mendoza and Hartzell [1988b] for Imperial Valley). Borehole data available in the epicentral region (e.g., TTRH02, SMNH01, TTR008, and SMN015) show that superficial sedimentary layers are thin (about $15 \mathrm{~m}$ ). These boreholes show rock materials (either granite or basalt) at depths between 15 and $100 \mathrm{~m}$. We have no information for depths greater than $100 \mathrm{~m}$. This relatively thin layer $(15 \mathrm{~m})$ of sediments in Tottori cannot be put forward to explain these two phenomena as it has been suggested for the Imperial Valley earthquake.

[36] According to the results of Fukuyama et al. [2003] the earliest aftershocks are concentrated in the SE part of the seismogenic region. The NW part was activated later with a large number of events concentrated in the region that did not slip during the main shock. The details of the horizontal distribution of the aftershocks indicates the existence of at least one plane NW of the epicenter almost perpendicular to the fault plane activated during the main shock. This plane is located where the dynamic rupture propagation in the NW direction stops. In this region, strongly loaded by the main shock, aftershocks are more abundant. This area is what Boatwright and Cocco [1996] called a slightly velocityweakening frictional behavior.

[37] The tests with different fault depths performed above (section 4.5) show that when slip is allowed to occur close to the surface, the variance reduction is increased. These tests confirm that slip actually occurred at shallow depth. Such shallow rupture with no surface rupture has been observed previously (e.g., Morgan Hill, in 1984; northern part of the Kobe earthquake, in 1995). This study of the 2000 Tottori earthquake benefits from a larger number of observations and definitely shows that large shallow asperities can occur without any surface break. This suggests that large strike slip earthquakes may have occurred in the past without cutting the surface. This phenomenon could complicate the interpretation of paleoseismological data. Return periods of damaging earthquakes could be overestimated if such shallow earthquakes with no surface rupture (blind fault) occurred. A more comprehensive study, beyond the scope of this investigation, should be performed in order to understand the geological and mechanical parameters that control the absence of surface slip of such shallow earthquakes.

[38] Finite sources simulations are used in seismic hazard studies to evaluate potential strong ground motion near faults. Empirical relationships have been proposed recently to evaluate the representative rupture properties of such simulations. Somerville et al. [1999] have proposed an empirical study where they quantify the asperities of 15 earthquakes and examined their average characteristics. Table 5 shows that the empirical relationships of Somerville et al. [1999] also predict the main features of the 2000 Tottori earthquake for a moment release rate of about $1.5 \times$ $10^{19} \mathrm{~N} \mathrm{~m}$. However, the studies of systematic features of asperities (e.g., rupture area, average slip) and their scaling with seismic moment for strong ground motion prediction do not commonly consider the relative asperity position on the fault plane. Our study shows that shallow and elongated asperities have to be taken into account in such simulations. Indeed, large asperities at shallow depth should have a significant contribution to ground motion. Such models, which could have been considered as extreme or unrealistic before the 2000 Tottori earthquake, are useful to capture the epistemic uncertainty of ground prediction or to evaluate maximum ground motion [Bommer et al., 2004].

[39] Acknowledgments. We thank Tomotaka Iwata for his precious advice regarding the strong motion records and Takeshi Sagiya for providing GPS data. We are grateful to Eichi Fukuyama and William Ellsworth, who kindly provided the catalog of aftershocks. Joan Gomberg, Honn Kao, and an anonymous reviewer made a many helpful suggestions on the paper. Comments by Michel Bouchon and Christophe Voisin helped to improve the first version of the manuscript. Thanks to KIK-net and K-net for providing strong motion data. Some figures are made using Generic Mapping Tools (GMT).

\section{References}

Aki, K. (1984), Asperities, barriers, characteristic earthquakes and strong motion prediction, J. Geophys. Res., 89, 5867-5872.

Beroza, G. C., and P. Spudich (1988), Linearized inversion for fault rupture behavior: Application for the 1984 Morgan Hill, California, earthquake, J. Geophys. Res., 93, 6275-6296.

Boatwright, J., and M. Cocco (1996), Frictional constraints on crustal faulting, J. Geophys. Res., 101, 13,895-13,910.

Bommer, J. J., et al. (2004), The challenge of defining upper bounds on earthquake ground motions, Seismol. Res. Lett., 75(1), 31.

Bonilla, L. F., F. Cotton, and R. J. Archuleta (2003), Quelques renseignements sur les effets de site non-linéaires en utilisant des données de forage: La base de mouvements forts KIK-Net au Japon (title in French, paper in English), paper presented at VIe Colloque National AFPS, Ecole Polytech., Palaiseau, France.

Campillo, M., and R. J. Archuleta (1993), A rupture model for the 28 June 1992 M7.4 Landers, California, earthquake, Geophys. Res. Lett., 20, $647-650$.

Campillo, M., and I. R. Ionescu (1997), Initiation of antiplane shear instability under slip-dependent friction, J. Geophys. Res., 102, 20,36320,371 . 
Cattin, R., P. Briole, H. Lyon-Caen, P. Bernard, and P. Pinettes (1999), Effects of superficial layers on coseismic displacements for a dip-slip fault and geophysical implications, Geophys. J. Int., 137, 149-158.

Cotton, F., and M. Campillo (1995), Inversion of strong ground motion in the frequency domain: Application to the 1992 Landers, California, earthquake, J. Geophys. Res., 100, 3961-3975.

Coutant, O. (1989), Program of numerical simulation AXITRA (in French), research report, Lab. de Geophys. Interne et Tectonophys., Grenoble, France.

Dalguer, L. A., K. Irikura, W. Zhang, and J. D. Riera (2002), Distribution of dynamic and static stress changes during 2000 Tottori (Japan) earthquake: Brief interpretation of the earthquake sequences; foreshocks, mainshock and aftershocks, Geophys. Res. Lett., 29(16), 1758, doi:10.1029/ 2001 GL014333.

Das, S., and K. Aki (1977), Fault planes with barriers: A versatile earthquake model, J. Geophys. Res., 82, 5648-5670.

Das, S., and B. V. Kostrov (1990), Inversion of seismic slip rate history and distribution with stabilizing constraints: Application to the 1986 Andreanof Islands earthquake, J. Geophys. Res., 95, 6899-6913.

Das, S., and B. V. Kostrov (1994), Diversity of solutions of the problem of earthquake faulting inversion; application to $S H$ waves for the great 1989 Macquarie Ridge earthquake, Phys. Earth Planet. Inter. 85, 293-318.

Das, S., and P. Suhadolc (1996), On the inverse problem for earthquake rupture: The Haskell-type source model, J. Geophys. Res., 101, 57255738.

Doser, D. I., and H. Kanamori (1986), Depth of seismicity in the Imperial Valley region (1977-1983) and its relationship to heat flow, crustal structure, and the October 15, 1979, earthquake, J. Geophys. Res., 91, $675-688$.

Ellsworth, W. L., and C. G. Beroza (1995), Seismic evidence for an earthquake nucleation phase, Science, 268, 851-855.

Freymueller, J. T., N. E. King, and P. Segall (1994), The co-seismic slip distribution of the Landers earthquake, Bull. Seismol. Soc. Am., 84, 646659.

Fukuyama, E., W. L. Ellsworth, F. Waldhauser, and A. Kubo (2003), Detailed fault structure of the 2000 western Tottori, Japan, earthquake sequence, Bull. Seismol. Soc. Am., 93, 1468-1478.

Hartzell, S. H., and T. H. Heaton (1983), Inversion of strong ground motion and teleseismic waveform data for the fault rupture history of the 1979 Imperial Valley, California earthquake, Bull. Seismol. Soc. Am., 73, $1553-1583$

Hartzell, S. H., and T. H. Heaton (1986), Rupture history of the 1984 Morgan Hill, California, earthquake from the inversion of strong motion records, Bull. Seismol. Soc. Am., 76, 649-674.

Hartzell, S. H., and C. Langer (1993), Importance of model parameterization in finite fault inversions; application to the $1974 M_{w} 8.0$ Peru earthquake, J. Geophys. Res., 98, 22,123-22,134.

Hartzell, S. H., and P. C. Liu (1995), Determination of earthquake source parameters using a hybrid global search algorithm, Bull. Seismol. Soc. Am., 85, 516-524.

Hartzell, S. H., and P. C. Liu (1996), Calculation of earthquake rupture histories using a hybrid global search algorithm: Application to the 1992 Landers, California, earthquake, Phys. Earth Planet. Inter., 95, 79-99.

Hartzell, S. H., S. S. Gordon, and C. Mendoza (1991), Comparison of L1 and L2 norms in a teleseismic waveform inversion for the slip history of the Loma Prieta, California, earthquake, Bull. Seismol. Soc. Am., 81 $1518-1539$

Hernandez, B., F. Cotton, and M. Campillo (1999), Contribution of radar interferometry to a two-step inversion of the kinematic process of the 1992 Landers earthquake, J. Geophys. Res., 104, 13,083-13,100.

Iio, Y. (1992), Slow initial phase of the $p$-wave velocity pulse generated by microearthquakes, Geophys. Res. Lett., 19, 477-480.

Iwata, T., and H. Sekiguchi (2002), Source process and near-source ground motion during the 2000 Tottori-ken Seibu earthquake, paper presented at 11th Japan Earthquake Engineering Symposium, Earthquake Eng. Res. Liaison Comm., Sci. Counc. of Jpn., Tokyo.

Ji, C., D. J. Wald, and D. V. Helmberger (2002), Source description of the 1999 Hector Mine, California, earthquake, Part II: Complexity of slip history, Bull. Seismol. Soc. Am., 92, 1208-1226.
Kagawa, T., K. Irikura, and P. G. Somerville (2004), Differences in ground motion and fault rupture process between the surface and buried rupture earthquakes, Earth Planets Space, 56(1), 3-14.

Liu, P., and R. J. Archuleta (2004), A new nonlinear finite fault inversion with three-dimensional Green's functions: Application to the 1989 Loma Prieta, California, earthquake, J. Geophys. Res., 109, B02318, doi:10.1029/2003JB002625.

Mendoza, C., and S. H. Hartzell (1988a), Inversion for slip distribution using teleseismic P waveforms: North Palm Springs, Borah Peak, and Michoacan earthquakes, Bull. Seismol. Soc. Am., 78, 1092-1111.

Mendoza, C., and S. H. Hartzell (1988b), Aftershock patterns and main shock faulting, Bull. Seismol. Soc. Am., 78, 1438-1449.

Mendoza, C., and S. H. Hartzell (1989), Slip distribution of the 19 September 1985 Michoacan, Mexico, earthquake: Near-source and teleseismic constraints, Bull. Seismol. Soc. Am., 79, 655-669.

Mikumo, T., and T. Miyatake (1978), Dynamical rupture process on a threedimensional fault with non-uniform frictions, and near-field seismic waves, Geophys. J. R. Astron. Soc., 54, 417-438.

Nakayama, W., and M. Takeo (1997), Slip history of the 1994 SanrikuHaruka-Oki, Japan, earthquake deduced from strong motion data, Bull. Seismol. Soc. Am., 87, 918-931.

Okada, Y. (1985), Surface deformation due to shear and tensile faults in a half-space, Bull. Seismol. Soc. Am., 75, 1135-1154.

Olson, A. H., and J. G. Anderson (1988), Implications of frequency-domain inversion of earthquake ground motions for resolving the space-time dependence of slip on an extended fault, Geophys. J., 94, 443-455.

Olson, A. H., and R. J. Apsel (1982), Finite fault and inverse theory with applications to the 1979 Imperial Valley earthquake, Bull. Seismol. Soc. Am., 72, 1969-2001.

Peltzer, G., F. Crampe, and P. Rosen (2001), The $M_{w}$ 7.1, Hector Mine, California earthquake: Surface rupture, surface displacement field, and fault slip solution from ERS SAR data, C. R. Acad. Sci., 333, 545-555.

Peyrat, S., and K. B. Olsen (2004), Nonlinear dynamic rupture inversion of the 2000 Western Tottori, Japan, earthquake, Geophys. Res. Lett., 31, L05604, doi:10.1029/2003GL019058.

Quin, H. (1990), Dynamic stress drop and rupture dynamics of the October 15, 1979 Imperial Valley, California earthquake, Tectonophysics, 175, $93-117$.

Sagiya, T., T. Nishimura, Y. Hatanaka, E. Fukuyama, and W. L. Ellsworth (2002), Crustal movements associated with the 2000 western Tottori earthquake and its fault models (in Japanese with English abstract), J. Seismol. Soc. Am., 54, 523-534.

Savage, J. C. (1998), Displacement field for an edge dislocation in a layered half-space, J. Geophys. Res., 103, 2439-2446.

Sekiguchi, H., K. Irikura, and T. Iwata (2000), Fault geometry at the rupture termination of the 1995 Hyogo-ken Nanbu earthquake, Bull. Seismol. Soc. Am., 90, 117-133.

Somerville, P., K. Irikura, R. Graves, S. Sawada, D. J. Wald, N. Abrahamson, Y. Iwasaki, T. Kagawa, N. Smith, and A. Kowada (1999), Characterizing crustal earthquake slip models for the prediction of strong ground motion, Seismol. Res. Lett., 70, 59-80.

Takeo, M. (1987), An inversion method to analyze the rupture process of earthquakes using near-field seismograms, Bull. Seismol. Soc. Am., 77, $490-513$.

Tarantola, A. (1987), Inverse Problem Theory, Elsevier, New York.

Tarantola, A., and B. Valette (1982), Generalized nonlinear inverse problems solved using the least squares criterion, Rev. Geophys., 20, 219232.

Uhrhammer, R., and B. A. Bolt (1991), The seismic magnitude of the 1989 Loma Prieta mainshock determined from strong motion records, Bull. Seismol. Soc. Am., 81, 1511-1517.

Waldhauser, F., and W. L. Ellsworth (2000), A double-difference earthquake location algorithm: Method and application to the northern Hayward fault, Bull. Seismol. Soc. Am., 90, 1353-1368.

M. Campillo, F. Cotton, and F. Semmane, Laboratoire de Géophysique Interne et Tectonophysique, Université Joseph Fourier, BP53, F-38041 Grenoble, France. (campillo@obs.ujf-grenoble.fr; fcotton@obs. ujf-grenoble.fr; fsemmane@obs.ujf-grenoble.fr) 